\title{
EDITORIAL
}

\section{On Research Contributions Presented During The Italian Great Network Meeting In Rome (October 15-18 2012)}

\author{
Salvatore Di Somma and Angelo Ianni
}

\section{Emergency Medicine Sant'Andrea Hospital Rome; Faculty of Medicine and Psychology University of Rome Sapienza Rome, GREAT Network Italy}

Innovation and Research are the driving force that induces advances in medicine in general, and in emergency medicine in particular. The GREAT Network is an Academic Research Organization, operating as an International cooperation between experts in the management of acute diseases. The GREAT Network also aims at standardizing the clinical and organizational approach in acute conditions management, with the concept of globalization health care.

The main objective of the team is to let the researchers networking with the concept of Translational Medicine, which is the emerging view of medical practice and interventional epidemiology. It integrates basic and clinical research inputs to optimize both patient and preventive care. In this attempt last year during the meeting in Rome (October 15-18 2012) a particular attention was dedicated to biomarkers utility in the emergency room.

Every day there were debating and interactive sessions where the best international experts from different backgrounds (Emergency physicians, cardiologists, intensivists, clinical biochemistries, radiologists, neurologists, nephrologists, gastroenterologists, surgeons, orthopaedists, pediatricians, lung specialists, basic researchers, nurses, engineers, etc.) worked together to analyze research results in several acute diseases management. The articles in this issue of the journal represent the selected and awarded research

*Address correspondence to these authors at the Department of Emergency Medicine, Medical-Surgery Sciences and Translational Medicine, S, Andrea Hospital, 'Sapienza' University, via di Grottarossa 1035-1039, Rome 00189, Italy. Tel: +39.06 .33775592 ; Fax: +39.06 .33775890 ;

E-mail: salvatore.disomma@uniroma1.it contributions presented during last edition of the Italian GREAT network in Rome and represent innovative messages in the field of Emergency medicine.

The first paper of PINTO et al. describes the role of the POSSUM score in the stratification of patients undergoing extrabdominal surgery. POSSUM score seems to be an adequate preoperative tool in order to evaluate and to determine the real condition of a patients after surgery and the appropriate requirement of an admission to postoperative ICU.

The second contribution from ANTONINI et al demonstrated that the Microbiological Survey Methods could represents a worthy aid in clinical microbiology as a POCT device to be used for urinary tract infection patients. in the Emergency setting. The article on the role of high level of Angiopoietin-2 in patients with SIRS/sepsis, at time of hospital admission seems to be predictive for early mortality and kidney, lung and hemostasis dysfunction. DE BIASE et al. suggest that red blood cells distribution could be a routine and inexpensive test that can provide information concerning severity and clinical condition in acute phase of an acute coronary syndrome. RICEVUTI et al. describe the usefulness of clinical pre-test scores for a correct diagnostic pathway in patients with suspect pulmonary embolism in emergency room. RICEVUTI. also present a study on the use of antibiotics for epidermal wounds in emergency room, for an appropriate prophylaxis and right choice of the treatment.

All these research contributions are based on the concept of Translational and Innovative medicine and could be considered the right way to increase the scientific skill of Emergency physicians, in the next future.

The GREAT NETWORK seems to provide the opportunity to realize this reality.

(C) Somma and Ianni; Licensee Bentham Open.

This is an open access article licensed under the terms of the Creative Commons Attribution Non-Commercial License (http://creativecommons.org/licenses/ by-nc/3.0/) which permits unrestricted, non-commercial use, distribution and reproduction in any medium, provided the work is properly cited. 